\title{
Hepatitis B Virus Screening and Real Life Data in Patients with Solid Tumor Receiving Chemotherapy
}

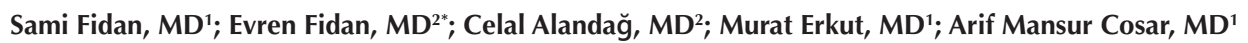 \\ 'Department of Gastroenterology, Faculty of Medicine, Karadeniz Technical University, Trabzon, Turkey \\ ${ }^{2}$ Department of Medical Oncology, Faculty of Medicine, Karadeniz Technical University, Trabzon, Turkey
}

\begin{abstract}
Background: Reactivation of the hepatitis B virus (HBV) either during or after chemotherapy may cause serious and sometimes fatal hepatitis. All patients undergoing chemotherapy should therefore be screened in terms of HBV before chemotherapy. The purpose of this research was to identify HBV screening rates in patients with solid cancer undergoing parenteral chemotherapy and to determine the outcomes of patients undergoing HBV screening.

Methods: Data for patients undergoing parenteral chemotherapy for solid cancer from January 1, 2012 to December 30, 2018 were retrieved from our electronic health record patient files in this retrospective study. Screening was defined as hepatitis B surface antigen ( $\mathrm{HBsAg})$ and/or hepatitis B core antibody ( $\mathrm{HBcAb})$ tests carried out within six months prior the first chemotherapy session.

Results: Four thousand fifty-eight (63\%) of the 6440 patients who underwent parenteral chemotherapy were screened for $\mathrm{HBsAg}$ and/or HBcAb. The proportions of patients screened for HBsAg and HBcAb improved from 38.8\% (2012) to 76.3\% (2018), and from $0.2 \%$ (2012) to $43 \%$ (2018), respectively $(P<0.001)$. The HBsAg and HBcAb positivity rates were $2.9 \%$ and $36.5 \%$, respectively. Antiviral prophylaxis was started in $11.8 \%$ of $\mathrm{HBsAg}$-negative/HBcAb-positive patients and $40.5 \%$ of $\mathrm{HBsAg}$-positive patients. HBV reactivation did not occur in patients receiving antiviral prophylaxis, but was identified in $7.2 \%$ of $\mathrm{HBsAg-positive}$ patients and $0.6 \%$ of $\mathrm{HBsAg}$-negative/HBcAb-positive patients without antiviral prophylaxis.

Conclusion: Although HBV screening rates before chemotherapy are increasing among solid cancer patients, the rate of initiation of antiviral prophylaxis is still low. It is therefore important to raise awareness regarding HBV reactivation during/after chemotherapy. Keywords: Chemotherapy, Hepatitis B virus, Malignancy, Reactivation, Solid tumours

Cite this article as: Fidan S, Fidan E, Alandağ C, Erkut M, Cosar AM. Hepatitis B virus screening and real life data in patients with solid tumor receiving chemotherapy. Arch Iran Med. 2020;23 (12):835-841. doi: 10.34172/aim.2020.111.
\end{abstract}

Received: August 22, 2019, Accepted: May 10, 2020, ePublished: December 1, 2020

\section{Introduction}

The hepatitis B virus (HBV) infection is an important global health problem. According to the World Health Organization data, approximately 257 million people are chronically infected with HBV. ${ }^{1}$ Since the viral genomic structure persists in the hepatocyte nucleus in individuals infected with HBV (hepatitis B surface antigen [HBsAg]positive and/or hepatitis B core antibody [HBcAb]positive), these patients are at risk of HBV reactivation when undergoing chemotherapy or immunosuppressive therapy. ${ }^{2-4} \mathrm{HBV}$ reactivation rates in chemotherapy patients depend on HBV infection status and host factors, in addition to the chemotherapy regimen. ${ }^{5,6}$ Although chemotherapy-induced $\mathrm{HBV}$ reactivation is more common in patients with positive $\mathrm{HBsAg}$, reactivation may also occur in HBsAg-negative/HBcAb-positive individuals. ${ }^{7}$ HBV reactivation presents in a wide spectrum, from an asymptomatic clinical course to severe hepatitis, and sometimes even death due to fulminant hepatic failure., ${ }^{4,8}$ HBV reactivation in cancer patients may also result in delayed or termination of curative oncological treatment, potentially increasing the risk of morbidity and mortality. ${ }^{9}$ HBV screening prior to commencement of chemotherapy and prophylactic antiviral therapy in appropriate patients constitute one of the best ways to prevent HBV reactivation. ${ }^{10}$ Prophylactic antiviral therapies have been shown to be more effective than pre-emptive strategies in preventing HBV reactivation. ${ }^{11,12}$ The ideal approach for preventing HBV reactivation is therefore to start $\mathrm{HBV}$ prophylaxis in appropriate patients before chemotherapy.

Current gastroenterology guidelines recommend that all patients should be evaluated for $\mathrm{HBsAg}$, hepatitis B surface antibody (HBsAb) and $\mathrm{HBcAb}$ before chemotherapy, and that all HBsAg-positive patients should be checked for antiviral therapy or prophylaxis. In addition, if the patient is HBsAg-negative but HBcAb-positive, and at high risk of HBV reactivation, prophylaxis should be also administered. ${ }^{13-15}$ However, it is still unclear whether patients receiving chemotherapy receive proper screening for $\mathrm{HBV}$ as recommended by the guidelines. We report the results of a retrospective observational study of HBV screening rates in patients with solid cancer undergoing 
parenteral chemotherapy in a large university hospital. We also evaluated the rates of onset of antiviral prophylaxis and HBV reactivation among patients receiving chemotherapy who underwent HBV testing.

\section{Materials and Methods}

Study Populations and Data Sources

Solid cancer patients undergoing parenteral chemotherapy at the Karadeniz Technical University Medical Faculty Hospital, Turkey, between January 1, 2012 and December 30, 2018 were included in the study. Data were retrieved from our electronic health records using search terms (keywords and ICD codes), patient files, and the laboratory recording system. Patients diagnosed with solid cancer were first identified using ICD codes (C.00-C.75) from our hospital's electronic database. These patients' file numbers, age at time of diagnosis, gender, and dates of initial parenteral chemotherapy and hepatitis B serology tests were then determined. Patients who received intraperitoneal, intra-pleural, intra-bladder, etc. chemotherapy, or receiving only targeted or hormonal therapy without immunosuppressive effects, or not receiving chemotherapy for any reason were excluded. ${ }^{5,16,17}$ Patients with primary liver cancer were excluded due to the etiological relationship between HBV and hepatocellular carcinoma. ${ }^{18} \mathrm{We}$ also excluded patients who received antiviral treatment for HBV infection prior to chemotherapy, and those who were under 18 years of age. A flow chart of the study participants is shown in Figure 1.

\section{Methods and Definitions}

Screening was defined as $\mathrm{HBsAg}$ and/or $\mathrm{HBcAb}$ tests ordered within six months before the first chemotherapy session. ${ }^{4,19}$ HBsAb screening rates were also investigated. Positive findings on both $\mathrm{HBsAg}$ and $\mathrm{HBcAb}$ tests were regarded as chronic $\mathrm{HBV}$ infection, while $\mathrm{HBsAg-negative}$ and $\mathrm{HBcAb}$-positive cases were regarded as occult HBV infection or resolved $\mathrm{HBV}$ infection. ${ }^{19} \mathrm{HBV}$ reactivation was defined as an abrupt increase in HBV DNA replication (10-fold or more) from baseline values or the reappearance of HBV DNA in serum, or reverse seroconversion from $\mathrm{HBsAg}$-negative to $\mathrm{HBsAg}$-positive, with or without increased hepatic enzymes. ${ }^{20,21}$ We evaluated whether antiviral prophylaxis was initiated based on the HBV test results. During the study period, serological markers, including $\mathrm{HBsAg}, \mathrm{HBs} \mathrm{Ab}$ and $\mathrm{HBcAb}$ levels, were measured using electrochemiluminescence immunoassay on a Roche Cobas E601 device (Japan). Serum HBV DNA levels were determined using the real-time PCR method on a Roche Cobas AmpliPrep device (Japan) (lower limit of detection, $12 \mathrm{IU} / \mathrm{mL}$ ). Routine biochemical parameters were assayed on a Roche Hitachi Cobas 8000 autoanalyzer (Roch, Germany).

\section{Statistical Analysis}

Statistical Program for Social Sciences software (SPSS 23.0 for Windows; SPSS Inc., Chicago, IL, USA) was employed for all statistical analyses. Descriptive statistics were expressed as number and percentage for categorical variables and as mean \pm standard deviation for numerical variables. Confidence intervals were calculated by Wilson method with continuity correction. Normal distribution of numerical variables was analyzed using the KolmogorovSmirnov test and Q-Q plot. The Mann-Whitney U test was employed in the comparison of numerical variables between two independent groups. Pearson's chi-square test was applied to evaluate the relationship between HBV screening status and gender, and the linear-by linear association test (chi-square for trend) to evaluate HBV screening rates and antiviral prophylaxis initiation rates before chemotherapy by years. The screening rates for each cancer type were compared according to the screening rate of the gastrointestinal cancer group. The test requirement for Pearson chi-square test, the number of expected counts below five, was checked before performing the Pearson chi-square test. Statistical significance was set at $P<0.05$.

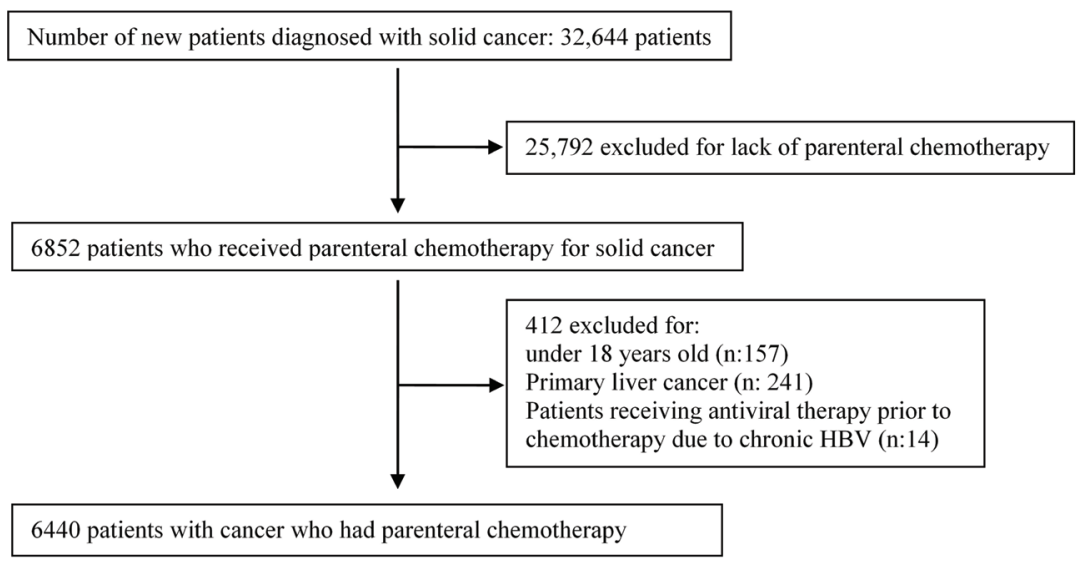

Figure 1. Flow Chart of Patients Enrolled in This Analysis. 


\section{Results}

A total of 6440 adult patients received parenteral chemotherapy for solid cancer between January 1, 2012 and December 30, 2018. The average age of the patient group at the time of chemotherapy was 58 years, and the majority were men $(54.1 \% ; n=3482)$. The most common malignancies were gastrointestinal $(28.9 \%)$, respiratory (25.1\%) and breast cancers (22.4\%). HBV screening rates differed according to cancer types (Pearson chi-square, p: 0.03). HBV Screening rate was highest in soft tissue tumors $(70.1 \%)$ followed by gastrointestinal (65.3\%) and respiratory system (64.6\%) tumors. The distribution of the solid tumors and characteristics of these patients are given in Table 1. Of the 6440 patients who received chemotherapy, 4058 (63\%) underwent screening for $\mathrm{HBsAg}$ and/or $\mathrm{HBcAb}$ before the first chemotherapy session. Overall, $62.9 \%$ of patients $(n=4050)$ underwent screening for HBsAg, 52.5\% ( $\mathrm{n}=3379)$ for $\mathrm{HBsAb}$, and $18.9 \%(n=1218)$ for HBcAb before chemotherapy. The screening rates for $\mathrm{HBsAg}, \mathrm{HBsAb}$ and $\mathrm{HBcAb}$ improved from $38.8 \%$ (2012) to $76.3 \%$ (2018), from $31.2 \%$ (2012) to $67.6 \%$ (2018), and from $0.2 \%$ (2012) to $43 \%$ (2018), respectively (chi-square for trend, $P<0.001$ ) (Figure 2 ). $\mathrm{HBsAg}, \mathrm{HBsAb}$ and $\mathrm{HBcAb}$ positivity rates among the patients screened for HBV serological markers were 2.9\% (116/4050), 31.5\% (1066/3379), and 36.5\% (445/1218), respectively. The prevalence of a positive $\mathrm{HBcAb}$ result with a negative HBsAg test was 33.9\% (396/1169). HBV DNA was tested in only $25(21.5 \%)$ of the 116 patients with $\mathrm{HBs} A g$ positivity, and five were identified as $\mathrm{HBV}$ -
DNA-positive. HBV-DNA was tested in only 5 (1.3\%) of the 396 patients identified as $\mathrm{HBsAg}$-negative/ $\mathrm{HBcAb}$ positive, none of whom were HBV-DNA-positive. Fortyseven $(40.5 \%)$ of the 116 patients who tested positive for $\mathrm{HBsAg}$ before chemotherapy received prophylactic antiviral treatment, and none exhibited HBV reactivation, whereas five $(7.2 \%)$ of the 69 patients with no antiviral prophylaxis had HBV reactivation. Four of the patients exhibiting reactivation were treated with pre-emptive antiviral therapy, while one was not. Two of these patients exhibited no deterioration in clinical and laboratory tests, while three had elevated transaminases. No mortality was seen in any of the patients with reactivation. Fortyseven $(11.8 \%)$ of the 396 patients identified as HBsAgnegative/HBcAb-positive before chemotherapy received prophylactic antiviral treatment, and no $\mathrm{HBV}$ reactivation was detected in any of these, whereas two $(0.6 \%)$ of the 349 patients with no antiviral prophylaxis exhibited HBV reactivation (Table 2). Two patients exhibiting reactivation received pre-emptive antiviral therapy. One of the patients who developed reactivation was successfully treated with rescue therapy, while the second died due to liver failure. A marked time-dependent increase was observed in rates of initiation of antiviral prophylaxis in patients identified as $\mathrm{HBsAg-positive} \mathrm{before} \mathrm{chemotherapy} \mathrm{(chi-square} \mathrm{for}$ trend, $P=0.04)$. None of the HBsAg-negative/HBcAbpositive patients was started on prophylaxis before 2015 . Although the rates of patients started on prophylaxis rose after 2015, the increase was not statistically significant (chi-square for trend, $P=0.240$ ) (Figure 3).

Table 1. Characteristics and HBV Screening Pattern of the Study Population Before Chemotherapy

\begin{tabular}{|c|c|c|c|c|}
\hline Characteristics & $\begin{array}{c}\text { All patients } \\
6440(\% 100) \\
\text { n }\left[\%^{a}(95 \% \mathrm{CI})\right]\end{array}$ & $\begin{array}{c}\text { Screened patients }^{\mathrm{b}} \\
4058(\% 63) \\
\text { n }\left[\%^{\mathrm{c}}(95 \% \mathrm{Cl})\right]\end{array}$ & $\begin{array}{c}\text { Unscreened patients }^{d} \\
2382(\% 37) \\
\text { n }\left[\%^{d}(95 \% \mathrm{Cl})\right]\end{array}$ & $\begin{array}{c}P \text { value } \\
\text { [OR }(95 \% \text { C.I. })]\end{array}$ \\
\hline Age $($ Mean $\pm S D)$ & $58.3 \pm 12.8$ & $58.3 \pm 12.6$ & $58.6 \pm 13$ & $0.279^{*}$ \\
\hline \multicolumn{5}{|l|}{ Sex } \\
\hline Male & $3482[54.1(52.8-55.3)]$ & $2204[54.3(52.8-55.8)]$ & $127853.6(51.6-55.7)]$ & \multirow{2}{*}{$0.588[0.97(0.87-1.07)]^{* *}$} \\
\hline Female & 2958 [45.9 (44.7-47.2)] & $1854[45.7(44.2-47.2)]$ & $1104[46.4(44.3-48.4)]$ & \\
\hline Cancer type & & & & $0.003^{* * *}$ \\
\hline Gastrointestinal & $1861[28.9(27.8-30.0)]$ & $1216[65.3(63.1-67.5)]$ & $645[34.7(32.5-36.9)]$ & - \\
\hline Respiratory & 1617 [25.1 (24.7-26.2)] & $1044[64.6(62.8-66.9)]$ & $573[35.4(33.1-37.8)]$ & $0.632[0.96(0.84-1.11)]$ \\
\hline Breast & $1444[22.4(21.4-23.5)]$ & 851 [58.9 (56.3-61.5)] & $593[41.1(38.5-43.7)]$ & $0.001[0,76(0.66-0.87)]$ \\
\hline Genitourinary & $1111[17.3(16.3-18.2)]$ & 687 [61.8 (58.9-64.7)] & $424[38.2(35.3-41.1)]$ & $0.054[0.85(0.73-1.00)]$ \\
\hline Soft tissue & $117[1.8(1.5-2.1)]$ & 82 [70.1 (60.8-78.0)] & 35 [29.9 (22.0-39.2)] & $0.295[1.24(0.82-1.86)]$ \\
\hline Head and Neck & $105[1.6(1.3-2.0)]$ & $66[62.9(52.8-72.0)]$ & 39 [37.1 (28.1-47.2)] & $0.603[0.89(0.59-1.34)]$ \\
\hline Others & $185[2.9(2.5-3.3)]$ & 112 [60 (53.1-67.6)] & $73[40(32.4-47.0)]$ & $0.147[0.79(0.58-1.08)]$ \\
\hline
\end{tabular}

HBV, hepatitis B virüs; HBsAg, hepatitis B surface antigen; HBcAb, hepatitis B core antibody.

a The percentages represent column percentages.

b Patients screened for HBsAg and /or HBcAb within 6 months prior to first chemotherapy.

${ }^{c}$ The percentages represent row percentages.

d Patients not screened for HBsAg and /or HBcAb within 6 months prior to first chemotherapy.

"The Mann Whitney $U$ test.

"** Pearson Chi-square.

${ }^{* * *}$ Comparison of screening rates for each cancer type according to the rate of gastrointestinal cancer screening. 


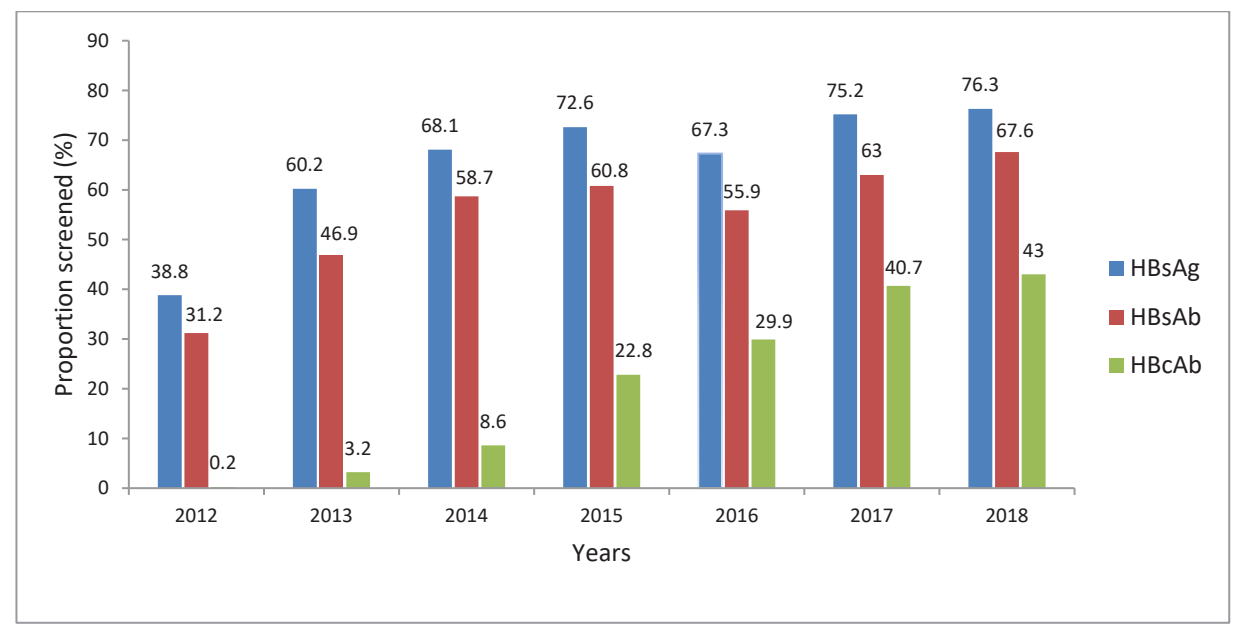

Figure 2. Series Annual Changes in $\mathrm{HbsAg}, \mathrm{HbsAb}$ and $\mathrm{HbcAb}$ Screening Rates Before Chemotherapy.

\section{Discussion}

$\mathrm{HBV}$ reactivation is a potentially significant complication seen in patients with HBV infection receiving chemotherapy or other immunosuppressive agents. In one meta-analysis, the rate of $\mathrm{HBV}$ reactivation in patients with chronic HBV undergoing chemotherapy for solid tumors without antiviral prophylaxis ranged from $4 \%$ to 68\% (median, 25\%). ${ }^{2}$ HBV reactivation can be largely avoided by means of prophylactic or early treatment with antiviral agents. ${ }^{2,10-12}$ However, initiation of antiviral treatment after chemotherapy-induced HBV reactivation is usually not effective in reducing hepatic damage and preventing progression to hepatic failure. ${ }^{11,22}$ Routine HBV screening in these patients before chemotherapy and the commencement of antiviral prophylaxis before developing HBV reactivation are therefore recommended by major gastroenterology guidelines. ${ }^{13-15}$

Studies have investigated HBV screening rates before chemotherapy in regions with low l, $, 18,23,24$ and high hepatitis B prevalence. ${ }^{19,20}$ According to the results of an epidemiological study from Turkey, the prevalence rates of $\mathrm{HBsAg}$ positivity and $\mathrm{HBcAb}$ positivity in the adult age group ( $\geq 18$ years) are $4 \%$ and $30.6 \%$, respectively. ${ }^{25}$ To the best of our knowledge, there have been no previous studies concerning pre-chemotherapy HBV screening in solid tumor cases in countries with a moderate prevalence of HBV, such as Turkey. This retrospective study investigated HBV screening rates before chemotherapy in patients undergoing chemotherapy for solid cancer in Turkey. The results showed that the overall HBV screening rate (defined as testing for $\mathrm{HBsAg}$ and/or $\mathrm{HBcAb}$ ) over the period 2012-2018 was 63\%, much lower than it should be. $\mathrm{HBsAg}, \mathrm{HBs} A b$ and $\mathrm{HBcAb}$ positivity rates among patients screened for HBV serological markers were 2.9\%, $31.5 \%$, and $36.5 \%$, respectively. The screening rates for $\mathrm{HBsAg}, \mathrm{HBsAb}$ and $\mathrm{HBcAb}$ improved from $38.8 \%$ (2012) to $76.3 \%$ (2018), from $31.2 \%$ (2012) to $67.6 \%$ (2018), and from $0.2 \%$ (2012) to $43 \%$ (2018), respectively.

Far lower HBV screening rates have been reported in patients receiving cancer chemotherapy than those recommended by guidelines. Studies conducted in low endemic areas for HBV such as Canada and the United States have reported overall HBV screening rates below $20 \%$. These studies have reported screening rates for solid cancers between $4 \%$ and $8.3 \% .^{4,5,16,19,23,24}$ Surveys conducted among oncologists in low-endemic areas

Table 2. HBV Screening and Treatment Rates of the Study Population Before Chemotherapy

\begin{tabular}{|c|c|c|c|c|c|}
\hline Screening Test & $\begin{array}{c}\text { Screening Test Performed } \\
\text { Before Chemotherapy } \\
\text { Patients/Total }[\%(95 \% \mathrm{Cl})]\end{array}$ & $\begin{array}{c}\text { Positive Test Result } \\
\text { Patients/Total } \\
{[\%(95 \% \mathrm{CI})]}\end{array}$ & $\begin{array}{c}\text { Antiviral Therapy Started } \\
\text { in Positive Test Result } \\
\text { Patients/Total } \\
{[\%(95 \% \mathrm{CI})]}\end{array}$ & $\begin{array}{l}\text { Antiviral Therapy Did not } \\
\text { Start in Positive Test Result } \\
\text { Patients/Total [\% (95\% } \\
\text { CI)] }\end{array}$ & $\begin{array}{c}\text { HBV Reactivation in } \\
\text { Patients not Receiving } \\
\text { Antiviral Prophylaxis } \\
\text { Patients/Total }[\%(95 \% \mathrm{CI})]\end{array}$ \\
\hline $\mathrm{HBsAg}$ & $\begin{array}{c}4050 / 6440 \\
{[62.9(61.7-64.1)]}\end{array}$ & $\begin{array}{c}116 / 4050 \\
{[2.9(2.4-3.4)]}\end{array}$ & $\begin{array}{c}47 / 116 \\
{[40.5(31.6-50.1)]}\end{array}$ & $\begin{array}{c}69 / 116 \\
{[59.5(50.0-68.4)]}\end{array}$ & $\begin{array}{c}5 / 69 \\
{[7.2(2.7-16.8)]}\end{array}$ \\
\hline $\mathrm{HBcAb} \operatorname{lgG} /$ total & $\begin{array}{c}1218 / 6440 \\
{[18.9(18.0-19.9)]}\end{array}$ & $\begin{array}{c}445 / 1218 \\
{[36.5(33.8-39.3)]}\end{array}$ & $\begin{array}{c}47 / 396^{*} \\
{[11.9(8.9-15.5)]}\end{array}$ & $\begin{array}{c}349 / 396 \\
{[88.1(84.4-91.1)]}\end{array}$ & $\begin{array}{c}2 / 349 \\
{[0.6(0.1-2.2)]}\end{array}$ \\
\hline $\mathrm{HBsAb}$ & $\begin{array}{c}3379 / 6440 \\
{[52.5(51.2-53.7)]}\end{array}$ & $\begin{array}{c}1066 / 3379 \\
{[31.5(30.0-33.2)]}\end{array}$ & $0 / 773^{* *}$ & $\begin{array}{c}773 / 773 \\
{[100.0(99.4-100.0)]}\end{array}$ & $0 / 773$ \\
\hline
\end{tabular}

HBV hepatitis B virus; HBsAg hepatitis B surface antigen; HBsAb hepatitis B surface antibody; HBcAb hepatitis B core antibody.

"Out of $445 \mathrm{HBcAb}$ positive patients, $49 \mathrm{HBsAg}$ positive patients were excluded.

"Out of $1066 \mathrm{HBsAb}$ positive patients, $293 \mathrm{HBsAg}$ and / or HBcAb positive patients were excluded. 


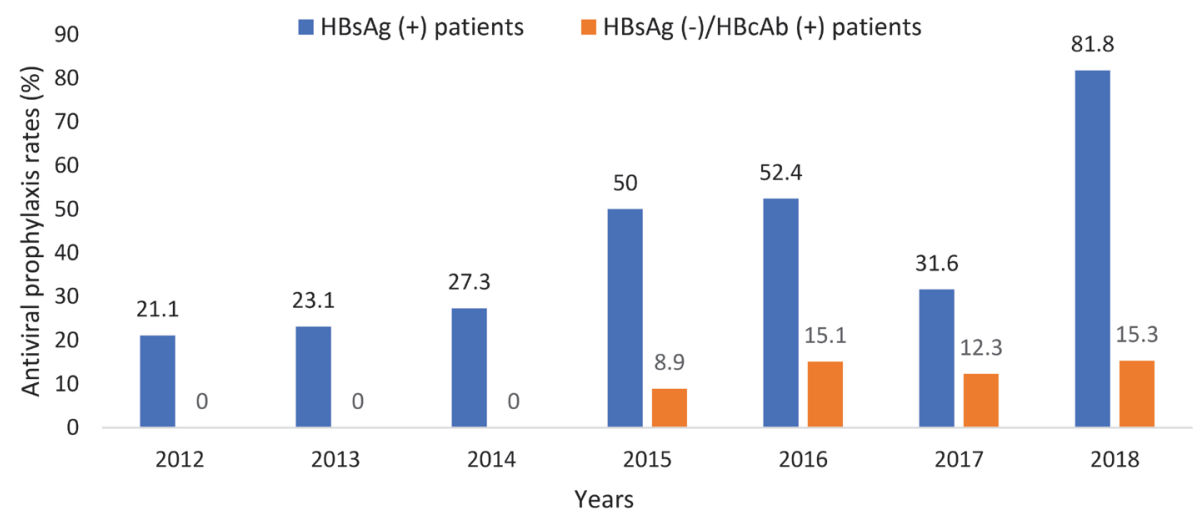

Figure 3. Antiviral Prophylaxis Rates in Hepatitis B Surface Antigen-Positive ( $n=116)$ and HbsAg-Negative/HbcAb-Positive $(n=396)$ Patients Undergoing Chemotherapy for Solid Tumors.

have revealed that only a small proportion of oncologists (13-22\%) report screening all patients receiving chemotherapy. ${ }^{21,26,27}$ The majority of oncologists generally screen for risk factors such as ethnicity or abnormal liver biochemistry. Even in high endemic areas, screening rates were low. In a study from China, only $17 \%$ of patients underwent pre-chemotherapy $\mathrm{HBV}$ tests. ${ }^{20}$ Similar to our own research, another study from Japan reported pre-chemotherapy screening rates of $66.3 \%$ and $19.9 \%$ for $\mathrm{HBsAg}$ and $\mathrm{HBcAb}$, respectively. ${ }^{19}$ These results indicate that the importance of $\mathrm{HBV}$ screening before chemotherapy is not fully understood yet. We therefore think that this may be due to various differences between oncology and gastroenterology guidelines in these patients. Although gastroenterology guidelines ${ }^{13-15}$ advice that all patients should be screened for HBV before chemotherapy, oncology guidelines ${ }^{28,29}$ recommend screening only patients receiving high-risk chemotherapy or those at high risk of reactivation. This leads to confusion among physicians applying chemotherapy. In addition, the fact that HBV reactivation is relatively uncommon in cases receiving chemotherapy or is ignored by physicians applying chemotherapy, and probable concerns over additional costs entailed by HBV screening, may also be responsible for low $\mathrm{HBV}$ screening rates.

HBV screening rates can be increased by raising the awareness regarding HBV reactivation among physicians applying chemotherapy and by using routine screening programs and/or alarm systems for HBV before chemotherapy. In a retrospective study of cancer patients in Canada, Lee et al reported an increase in pre-chemotherapy screening rates from $14 \%$ to $31 \%$ after training of principal members of the oncology team, including physicians and pharmacists. ${ }^{24} \mathrm{~A}$ recent retrospective study from Holland by Leber et al reported that the pre-chemotherapy HBV screening rate of $52.9 \%$ increased to $80.7 \%$ following the application of a routine HBV screening protocol. The screening rate in patients with solid tumors in that study rose from $22-58 \%$ to $42-98 \% .^{30}$ The use of an automated alarm system to monitor HBV status in electronic patient records prior to chemotherapy may help improve HBV screening results. In a study of patients receiving biological therapy, Sampedro et al showed that with the use of an alarm system before treatment, screening rates for $\mathrm{HBsAg}$ increased from $50 \%$ to $94 \%$ and those for $\mathrm{HBcAb}$ from $30 \%$ to $85 \% .^{31}$ In a study from 2009 , Sun et al reported that the screening rate of $26.8 \%$ for $\mathrm{HBs}$ Ag before cytotoxic chemotherapy increased to approximately $85.5 \%$ in the same hospital with the use of an alarm system. ${ }^{17}$

In our study, only $40.5 \%(47 / 116)$ of patients with $\mathrm{HBsAg}$-positive patients, who were at high risk of $\mathrm{HBV}$ reactivation, were started on antiviral prophylaxis prior to chemotherapy. However, the rates of starting antiviral prophylaxis in these patients improved significantly over the years $(P=0.04)$ (Figure 3$)$. Only 11.8\% (47/396) of $\mathrm{HBs} A$-negative/HBcAb-positive patients were started on antiviral prophylaxis. In agreement with our findings, previous studies have also reported low rates of initiation of antiviral prophylaxis in patients screened and testing positive for HBV. Sun et al investigated 1053 patients receiving cytotoxic chemotherapy and reported that only $45.5 \%$ (61/134) of HBsAg-positive patients before chemotherapy were started on antiviral prophylaxis. HBV reactivation rates in that study were $1.6 \%$ in patients receiving antiviral prophylaxis but $15.1 \%$ in those not receiving it. ${ }^{17}$ Chung et al performed a retrospective study of 8005 patients receiving chemotherapy in the Mayo Clinic in the USA and reported that eight $(61.5 \%)$ of the 13 patients identified as positive for $\mathrm{HBV}$ were started on antiviral prophylaxis and that no HBV reactivation occurred in them, while reactivation was identified in two of the five patients not started on antiviral prophylaxis. ${ }^{16}$ The best means of preventing HBV reactivation among patients testing positive for $\mathrm{HBV}$ is antiviral prophylaxis prior to chemotherapy. In the present study, no HBV reactivation was observed in patients started on antiviral prophylaxis, while reactivation was identified in $7.2 \%$ of the $\mathrm{HBsAg}$-positive patients not started on antiviral 
prophylaxis and in $0.6 \%$ of the $\mathrm{HBsAg}$-negative/ $\mathrm{HBcAb}-$ positive patients.

Our current study yielded important findings concerning both HBV screening rates and antiviral prophylaxis initiation rates in solid cancer patients undergoing chemotherapy. The principal limitations of our study are associated with its retrospective nature. No specific protocol was employed to detect all cases of HBV reactivation, and most patients had no HBV DNA data available at baseline or during chemotherapy. In addition, due to the retrospective nature of the present study, confounding factors which might have affected the outcome of the study could not be included in the analysis because of lack of information about possible confounders within the data, and the according adjustments could not therefore be made.

In conclusion, the overall rate of $\mathrm{HBV}$ screening before chemotherapy among patients with solid cancer undergoing parenteral chemotherapy during 2012-2018 was $63 \%$, but it increased over time. Additionally, we found that even among patients identified as $\mathrm{HBsAg-}$ positive before chemotherapy, fewer than half of patients were started on antiviral prophylaxis. More advances strategies are therefore needed both in order to improve levels of awareness regarding HBV reactivation among physicians applying chemotherapy and also to increase antiviral prophylaxis rates among appropriate patients.

\section{Authors' Contribution}

SF and EF contributed equally to the working concept and design. The critical revision of the article was made by EF, AMC, and ME. All authors have made significant contributions to the analysis and interpretation of the data. SF wrote the first draft of the manuscript, and all authors read and approved the last article.

\section{Conflict of Interest Disclosures}

The authors have no conflict of interest to declare.

\section{Ethical Statement}

The study was carried out in line with the principles of the Declaration of Helsinki and was approved by the local ethical committee of Karadeniz Technical University (No. 2018 /211).

\section{Funding}

No funding or financial support was received.

\section{References}

1. World Health Organization. Hepatitis B. Fact Sheet. Available from: https://www.who.int/en/news-room/fact-sheets/detail/ hepatitis-b. Accessed July 27, 2020.

2. Paul S, Saxena A, Terrin N, Viveiros K, Balk EM, Wong JB. Hepatitis B virus reactivation and prophylaxis during solid tumor chemotherapy: a systematic review and meta-analysis. Ann Intern Med. 2016;164 (1):30-40. doi: 10.7326/M151121.

3. Shouval D, Shibolet O. Immunosuppression and HBV reactivation. Semin Liver Dis. 2013;33 (2):167-77. doi: 10.1055/s-0033-1345722.

4. Hwang JP, Fisch MJ, Zhang H, Kallen MA, Routbort MJ, Lal LS, et al. Low rates of hepatitis B virus screening at the onset of chemotherapy. J Oncol Pract. 2012;8:e32-9. doi:10.1200/ JOP.2011.000450.

5. Kwak YE, Stein SM, Lim JK. Practice patterns in hepatitis B virus screening before cancer chemotherapy in a major US Hospital Network. Dig Dis Sci. 2018;63 (1):61-71. doi: 10.1007/s10620-017-4850-1.

6. Perrillo RP, Gish R, Falck-Ytter YT. American Gastroenterological Association Institute technical review on prevention and treatment of hepatitis B virus reactivation during immunosuppressive drug therapy. Gastroenterology. 2015;148 (1):221-44.e3. doi: 10.1053/j.gastro.2014.10.038.

7. Yeo W, Chan HL. Hepatitis B virus reactivation associated with anti-neoplastic therapy. J Gastroenterol Hepatol. 2013;28 (1):31-7. doi: 10.1111/j.1440-1746.2012.07280.x.

8. Hoofnagle JH. Reactivation of hepatitis B. Hepatology. 2009;49 (5 Suppl):S156-65. doi: 10.1002/hep.22945.

9. Liu JY, Sheng YJ, Ding XC, Tang H, Tong SW, Zhang DZ, et al. The efficacy of lamivudine prophylaxis against hepatitis $B$ reactivation in breast cancer patients undergoing chemotherapy: a meta-analysis. J Formos Med Assoc. 2015;114 (2):164-73. doi: 10.1016/j.jfma.2012.10.007.

10. Choi J, Lim YS. Characteristics, Prevention, and Management of Hepatitis B Virus (HBV) Reactivation in HBV-Infected Patients Who Require Immunosuppressive Therapy. J Infect Dis. 2017;216 (suppl 8):S778-84. doi: 10.1093/infdis/jix178.

11. Hsu C, Hsiung CA, Su IJ, Hwang WS, Wang MC, Lin SF, et al. A revisit of prophylactic lamivudine for chemotherapyassociated hepatitis B reactivation in non-Hodgkin's lymphoma: a randomized trial. Hepatology. 2008;47 (3):84453. doi: 10.1002/hep.22106.

12. Lau GK, Yiu HH, Fong DY, Cheng HC, Au WY, Lai LS, et al. Early is superior to deferred preemptive lamivudine therapy for hepatitis B patients undergoing chemotherapy. Gastroenterology. 2003;125 (6):1742-9. doi: 10.1053/j. gastro.2003.09.026.

13. Galle PR, Forner A, Llovet JM, Mazzaferro V, Piscaglia F, Raoul JL. European Association for the Study of the Liver Electronic address eee, European Association for the Study of the L: EASL Clinical Practice Guidelines: Management of hepatocellular carcinoma. J Hepatol. 2018;69:182-236.

14. Terrault NA, Lok ASF, McMahon BJ, Chang KM, Hwang JP, Jonas $\mathrm{MM}$, et al. Update on prevention, diagnosis, and treatment of chronic hepatitis B: AASLD 2018 hepatitis B guidance. Hepatology. 2018;67 (4):1560-99. doi: 10.1002/ hep. 29800.

15. Sarin SK, Kumar M, Lau GK, Abbas Z, Chan HL, Chen CJ, et al. Asian-Pacific clinical practice guidelines on the management of hepatitis B: a 2015 update. Hepatol Int. 2016;10 (1):1-98. doi: 10.1007/s12072-015-9675-4.

16. Wi Cl, Loo NM, Larson JJ, Moynihan TJ, Madde NR, Grendahl DC, et al. Low level of hepatitis B virus screening among patients receiving chemotherapy. Clin Gastroenterol Hepatol. 2015;13 (5):970-5; quiz e51. doi: 10.1016/j.cgh.2014.10.032.

17. Sun WC, Hsu PI, Yu HC, Lin KH, Tsay FW, Wang HM, et al. The compliance of doctors with viral hepatitis B screening and antiviral prophylaxis in cancer patients receiving cytotoxic chemotherapy using a hospital-based screening reminder system. PLoS One. 2015;10 (2):e0116978. doi: 10.1371/ journal.pone.0116978.

18. Hwang JP, Fisch MJ, Lok AS, Zhang H, Vierling JM, SuarezAlmazor ME. Trends in hepatitis B virus screening at the onset of chemotherapy in a large US cancer center. BMC Cancer. 2013;13:534. doi: 10.1186/1471-2407-13-534.

19. Ikeda M, Yamamoto H, Kaneko M, Oshima H, Takahashi H, Umemoto K, et al. Screening rate for hepatitis B virus infection in patients undergoing chemotherapy in Japan. Int J Clin Oncol. 2016;21 (6):1162-6. doi: 10.1007/s10147-016-09958.

20. Wang Y, Luo XM, Yang D, Zhang J, Zhuo HY, Zhang J, et al. Testing for hepatitis B infection in prospective chemotherapy patients: a retrospective study. World J Gastroenterol. 2013;19 
(6):923-30. doi: 10.3748/wjg.v19.i6.923

21. Tran TT, Rakoski MO, Martin P, Poordad F. Screening for hepatitis B in chemotherapy patients: survey of current oncology practices. Aliment Pharmacol Ther. 2010;31 (2):2406. doi: 10.1111/j.1365-2036.2009.04158.x.

22. Lau GK, Yiu HH, Fong DY, Cheng HC, Au WY, Lai LS, et al. Early is superior to deferred preemptive lamivudine therapy for hepatitis B patients undergoing chemotherapy. Gastroenterology. 2003;125 (6):1742-9. doi: 10.1053/j. gastro.2003.09.026.

23. Visram A, Chan KK, McGee P, Boro J, Hicks LK, Feld JJ. Poor recognition of risk factors for hepatitis $B$ by physicians prescribing immunosuppressive therapy: a call for universal rather than risk-based screening. PLoS One. 2015;10 (4):e0120749. doi: 10.1371/journal.pone.0120749.

24. Lee R, Vu K, Bell CM, Hicks LK. Screening for hepatitis B surface antigen before chemotherapy: current practice and opportunities for improvement. Curr Oncol. 2010;17 (6):32-8. doi: $10.3747 /$ co.v17i6.653.

25. Tozun N, Ozdogan O, Cakaloglu Y, Idilman R, Karasu Z, Akarca $U$, et al. Seroprevalence of hepatitis B and C virus infections and risk factors in Turkey: a fieldwork TURHEP study. Clin Microbiol Infect. 2015;21 (11):1020-6. doi: 10.1016/j.cmi.2015.06.028.

26. Day FL, Link E, Thursky K, Rischin D. Current hepatitis B screening practices and clinical experience of reactivation in patients undergoing chemotherapy for solid tumors: a nationwide survey of medical oncologists. J Oncol Pract. 2011;7 (3):141-7. doi: 10.1200/JOP.2010.000133.

27. Lee RS, Bell CM, Singh JM, Hicks LK. Hepatitis B screening before chemotherapy: a survey of practitioners' knowledge, beliefs, and screening practices. J Oncol Pract. 2012;8 (6):3258. doi: 10.1200/JOP.2012.000597.

28. Hwang JP, Somerfield MR, Alston-Johnson DE, Cryer DR, Feld JJ, Kramer BS, et al. Hepatitis B Virus Screening for Patients With Cancer Before Therapy: American Society of Clinical Oncology Provisional Clinical Opinion Update. J Clin Oncol. 2015;33 (19):2212-20. doi: 10.1200/JCO.2015.61.3745.

29. Artz AS, Somerfield MR, Feld JJ, Giusti AF, Kramer BS, Sabichi $A L$, et al. American Society of Clinical Oncology provisional clinical opinion: chronic hepatitis B virus infection screening in patients receiving cytotoxic chemotherapy for treatment of malignant diseases. J Clin Oncol. 2010;28 (19):3199-202. doi: 10.1200/JCO.2010.30.0673.

30. Leber K, Otten JM, Depla AC, Brandjes DP, Lauw FN. Introduction of routine hepatitis B screening for all patients receiving cancer treatment. Neth J Med. 2019;77 (1):19-24.

31. Sampedro B, Hernández-López C, Ferrandiz JR, Illaro A, Fábrega E, Cuadrado A, et al. Computerized physician order entry-based system to prevent HBV reactivation in patients treated with biologic agents: the PRESCRIB project. Hepatology. 2014;60 (1):106-13. doi: 10.1002/hep.27103. 